\title{
Bidirectional Power Flow Control in AC/DC Hybrid System under AC and DC Fault Conditions
}

\author{
Wai Wai Hnin \\ Department of Electricacl Power \\ Engineering \\ Yangon Technological University, \\ Yangon ,Myanmar \\ waihninep@gmail.com
}

\author{
Zarchi linn \\ Department of Electrical Power \\ Engineering \\ Yangon Technological University, \\ Yangon, Myanmar \\ zarchilinn@ytu.edu.mm
}

\author{
Soe Win \\ Department of Electrical Power \\ Engineering \\ Yangon Technological University, \\ Yangon, Myanmar \\ soewin.ep@ytu.edu.mm
}

\begin{abstract}
This paper presents a hybrid AC-DC microgrid to reduce the process of multiple conversion in an individual $\mathrm{AC}$ microgrid or DC microgrid. The proposed hybrid microgrid composes of both AC microgrid and DC microgrid connected together by bidirectional interlink converter (BIC). Utility grid, $150 \mathrm{kVA}$ diesel generator (DG) and $100 \mathrm{~kW}$ AC load are connected in AC microgrid. DC microgrid is composed of $\mathbf{1 0 0}$ kW photovoltaic array (PV), 20kW battery energy storage system (BESS) and 20kW DC load. The droop control technique is applied to control the system for power sharing within the sources in AC/DC hybrid microgrid in proportion to the power rating. When the faults occur at $\mathrm{AC}$ bus, protection signal applied to breaker for isolating the healthy and faulted system. When DC fault occurs at DC bus, DC breaker isolate the $\mathrm{AC}$ and DC bus. The system performance for power flow sharing on hybrid AC-DC microgrid is demonstrated by using MATLAB/SIMULINK.
\end{abstract}

Keywords—hybrid microgrid, droop control, power flow, AC fault, DC fault

\section{INTRODUCTION}

Recent technology development and practice in power system has witnessed increasing interests on the concept of "direct DC" [1]. In dc microgrid, the $\mathrm{dc}-\mathrm{dc}$ bidirectional converters play an important role in the control of the internal dc bus voltage and in maintaining the system power balance [2]. The use of modern DC loads for their benefits in terms of efficiency, cost and system that can eliminate the dc-ac, ac-dc power conversion stages and their power losses [3].A microgrid is a discrete energy system consisting of distributed energy sources and loads capable of operating in parallel with or independently from the main power grid [4]. In AC or DC microgrids multiple reverse conversions requirement, increases cost and intricacy of the circuit and will reduce the efficiency of the system [5]. Microgrid operates in gridconnected and islanded mode where in grid connected mode, MG connected parallel to main grid to either draw or supply to grid [6]. In the islanded mode, hybrid microgrid control power flow between the AC and DC microgrid through an interlinking converter [7]. The frequency in AC microgrid and DC voltage in DC microgrid are maintained stable in the acceptable ranges by the interlinking converter. Hybrid AC/DC microgrid are an emerging power distribution scheme which can more efficiently integrate local renewable energy sources based distributed generations (DGs) and energy storage systems (ESSs), and to provide high reliable power supply for the local loads compared to a pure ac or dc MG [8].

In hybrid AC/DC microgrid system, BIC control can be applied using the droop control scheme for power sharing between AC and DC subgrids [9]. In [3], droop control with frequency and voltage deviation based balancing inputs have been performed, indeed merging them into one droop converter working together with other converters, in order to determine the corresponding reference power. Based on the droop control theory, all controlled converters participate in load sharing following the corresponding droop slope [10]. Renewable and small scale units need power electronic converters to be integrated with the existing power grid [11]. Modern power electronic switches can operate at high frequencies. The higher the operating frequency, the smaller and lighter the transformers, filter inductors, and capacitors [12]. The BIC should be able to control and manage power properly in both operating mode, grid-connected mode and stand-alone mode Operating the microgrid in stand-alone mode would lead to more challenges, particularly when the imbalance of generation and consumption happen because of flexible load and resources [13].

In AC/DC Hybrid microgrid system, one system is failure as disturbance, the protection scheme protect the another system. When the fault occurs at AC bus, DC bus power flow is maintained after isolation. The proposed coordination control strategy between the BIC and BESS converters can facilitate a smooth transition of the power transfer between $\mathrm{AC}$ and DC subgrids using the available resources and the last load. For overcurrent protection, the threshold setting of AC/DC link breaker and AC generator breaker are set $120 \%$ of full load current.

\section{AC/DC HYBRID MICROGRID CONFIGURATION}

This paper focuses on grid connected and standalone hybrid microgrid based on PV system, DG, BESS, AC loads and DC load. Fig 1 illustrates the proposed AC/DC hybrid microgrid model. The AC bus and DC bus are connected through $150 \mathrm{~kW}$ Bidirectional Interlink Converter (BIC). BIC is composed of bidirectional DC-DC converter and bidirectional DC-AC converter and also consists of isolation transformer. When the system faults or short circuit occur at one side, this transformer will isolate another bus to protect the system. Power management and frequency/voltage stabilization are performed by droop control strategies in $\mathrm{BIC}$. The power source on the AC side of the microgrid is a $150 \mathrm{kVA}$ diesel generator whereas the AC load is composed of $100 \mathrm{~kW}$. Power sources on the DC side of microgrid are $100 \mathrm{~kW}$ PV system through DC/DC boost converter, a battery energy storage system with a rating of $20 \mathrm{~kW}$ which is connected through DC/DC bidirectional buck/boost converter. $20 \mathrm{~kW}$ DC load is connected to DC bus. 


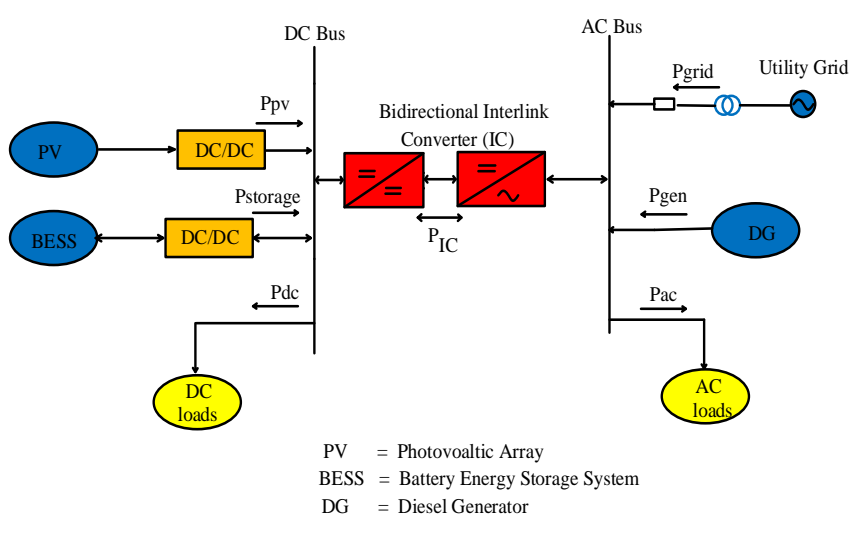

Fig 1. AC/DC hybrid microgrid configuration

\section{CONTROL STRATEGIES IN AC/DC HYBRID MICROGRID}

In microgrid, the system reliability and stability are achieved by the voltage regulation when more micro sources are interconnected. This voltage regulation damps the reactive power oscillations and voltage. In a complex power system, when multiple DGs are attached to the microgrid, the power sharing among them is done properly with the help of a control strategy called droop control. Droop control also enables the system to disconnect smoothly and reconnect routinely to the complex power system [14].

\section{A. Droop control in BIC}

In this study, the BIC connects the $\mathrm{AC}$ and $\mathrm{DC}$ grids and control the frequency of AC grid or DC voltage of DC grid. The control block diagram of the BIC is shown in Fig.2. The status of power in AC and DC grids is represented by the state of the hybrid microgrid that defines the control objectives such as frequency or DC voltage. The AC droop control and DC droop control equations are shown in equation (1) to (5).

$$
\begin{aligned}
& \cdot \Delta \mathrm{f}=\frac{\mathrm{f}_{\text {ref }}-\mathrm{f}_{\mathrm{m}}}{\mathrm{f}_{\text {ref }}} \\
& \Delta \mathrm{V}_{\mathrm{dc}}=\frac{\mathrm{V}_{\mathrm{dc}, \mathrm{ref}}-\mathrm{V}_{\mathrm{dc}, \mathrm{m}}}{\mathrm{V}_{\mathrm{dc}, \text { ref }}} \\
& \Delta \mathrm{P}=\left(\Delta \mathrm{f}-\Delta \mathrm{V}_{\mathrm{dc}}\right) \times \frac{1}{\mathrm{R}_{\mathrm{p}}} \\
& \mathrm{P}_{\mathrm{IC}}^{*}=\mathrm{P}_{\mathrm{IC}, 0}+\Delta \mathrm{P} \\
& \Delta \mathrm{Q}=\left(\mathrm{V}_{\mathrm{ac}, \mathrm{ref}}-\mathrm{V}_{\mathrm{ac}, \mathrm{m}}\right) \times \frac{1}{\mathrm{R}_{\mathrm{q}}}
\end{aligned}
$$

where,

$$
\begin{aligned}
\Delta \mathrm{f} & =\text { frequency deviation } \\
\mathrm{f}_{\mathrm{ref}} & =\text { reference frequency } \\
\mathrm{f}_{\mathrm{m}} & =\text { measured frequency } \\
\Delta \mathrm{V}_{\mathrm{dc}} & =\text { voltage deviation on DC Microgrid, } \\
\mathrm{V}_{\mathrm{dc}, \text { ref }} & =\text { reference DC voltage }
\end{aligned}
$$

$\mathrm{V}_{\mathrm{dc}, \mathrm{m}}=$ measured DC Voltage

$\Delta \mathrm{P}=$ active power reference

$\mathrm{P}_{\mathrm{IC}}^{*}=$ active power reference of IC

$\Delta \mathrm{Q}=$ reactive power reference

$\frac{1}{\mathrm{R}_{\mathrm{p}}}=$ gain parameter of $\mathrm{AC}$

$\frac{1}{\mathrm{R}_{\mathrm{q}}}=$ gain parameter of $\mathrm{DC}$

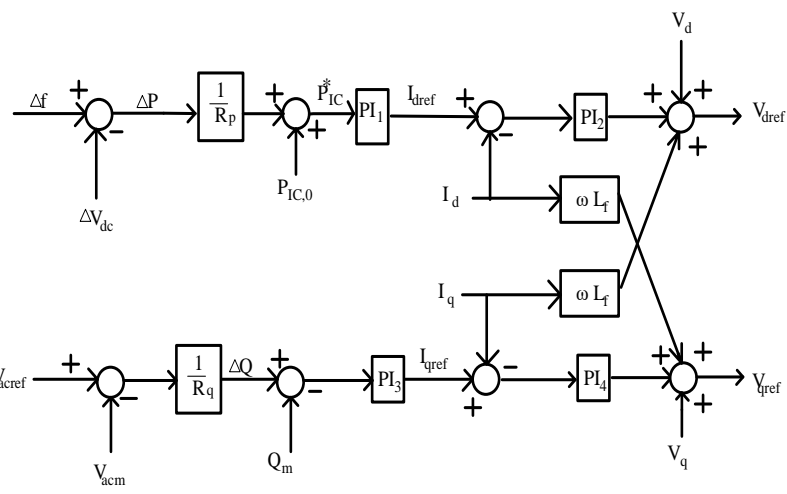

Fig 2. Control block diagram of the Bidirectional Interlinking Converter

The outer control loop which regulates $\mathrm{V}_{\mathrm{dc}}$ and $\mathrm{V}_{\mathrm{dc} \text {-ref }}$ and the inner control loop which regulates $I_{d}$ and $I_{q}$. Direct axis current component $\left(\mathrm{I}_{\mathrm{d}}\right)$ is used to control the DC link voltage and quadrature axis current component $\left(\mathrm{I}_{\mathrm{q}}\right)$ is used to regulate the reactive power. $\mathrm{I}_{\mathrm{d}}$ current reference is determined from the output of the $\mathrm{DC}$ voltage external controller. $\mathrm{I}_{\mathrm{q}}$ current reference is set to zero considering for zero reactive power. Voltage output converted from $\mathrm{V}_{\mathrm{d}}$ and $\mathrm{V}_{\mathrm{q}}$ in the current control loop are supplied to the Pulse Width Modulation (PWM) generator. PWM uses to supply the gate signals of AC-DC converter to obtain the stable output. It gives to reduce harmonics and to smooth the output. A phase locked loop (PLL) is device that causes one signal to track another signal. It is an important mechanism for synchronizing dc-to-ac converters with power grids [15]. PLL determines a signal to track another so that the output signal is synchronized with the input one both in frequency and phase.

\section{B. Battery Charged/Discharged Controller}

Fig 3. shows the block diagram of the charge/discharge controller. Generally, the switching losses of the IGBTs are high compared to the diodes; however, these can be reduced by eliminating unnecessary switching. Depending on the mode of operation, only one IGBT is needed to be switched at a predefined frequency. In order to select the proper IGBT, the reference current is compared to zero. If the reference current is negative, the controlled PWM signal is sent to $S_{1}$, activating the buck mode of operation. On the other hand, if the current reference is positive, the signal is sent to $S_{2}$ to transfer energy from the LV side to the HV side, activating the boost mode of operation [16]. 


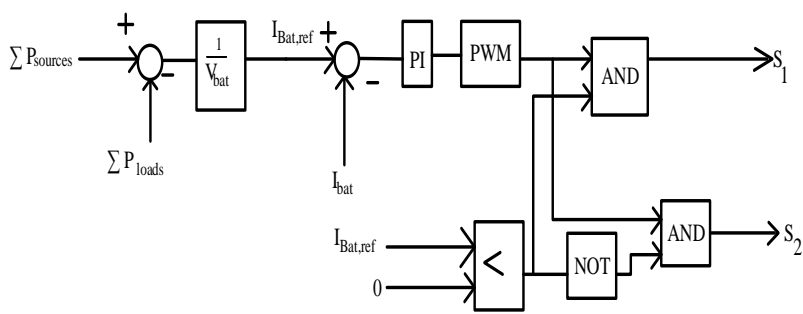

Fig 3. Block diagram of battery charged/discharged controller

\section{SIMULATION RESULTS AND CONDITIONS}

\section{A. Simulation Case}

In order to confirm the control strategies of the AC/DC microgrid, computer simulations were carried out by using MATLAB/SIMULIMK. In this simulation, the converter switching losses is neglected. The main parameters of this system are shown in Table I and the simulation model is shown in Fig 5. In this paper, three cases of simulation were carried out considering for both grid-connected and standalone conditions. They are;

Case (I) : Irradiation changes

Case (II) : DC fault and

Case (III) : AC fault are considered.

\section{B. Simulation results}

a) Case (I) : Irradiation changes

In this case, considering the stand alone mode, grid and generator are off at $\mathrm{AC}$ bus. PV system is operating with the irradiation changing $\left(1000,800,600 \mathrm{~W} / \mathrm{m}^{2}\right)$ shown in Fig 4(a). At $0-0.5 \mathrm{~s}, \mathrm{PV}$ system produces $100 \mathrm{~kW}$ and $20 \mathrm{~kW}$ from the energy storage (BESS) system shown in Fig 4(d). The power produced by $\mathrm{PV}$ is reducing depending on Irradiation change. However DC load is constant at $20 \mathrm{~kW}$ and AC load is $80 \mathrm{~kW}$ as shown in Fig 4(b) and (c). When the PV power is not sufficient for power demand, the BEES produces the required power for loads. The reference voltage is $780 \mathrm{~V}$ and the mean voltage is the same as the reference voltage that is shown in Fig 4(e).

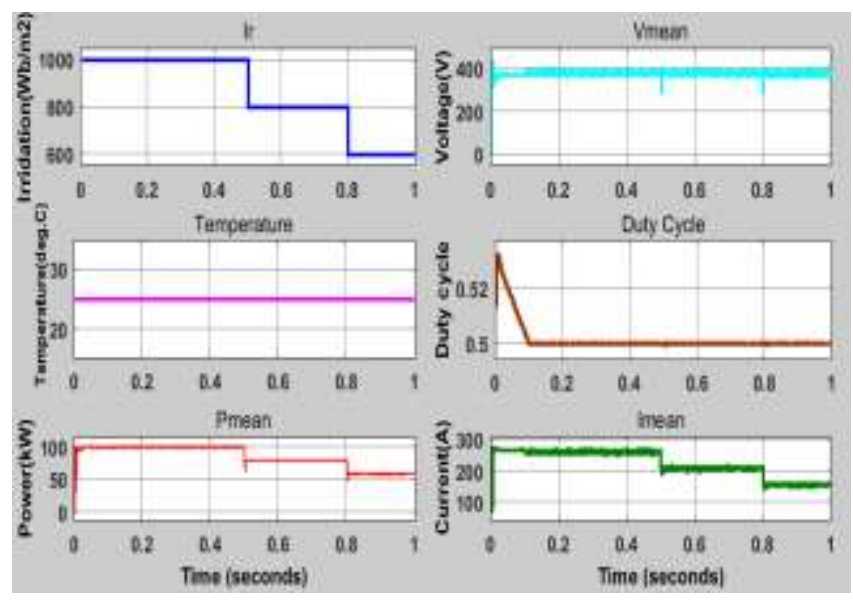

(a)

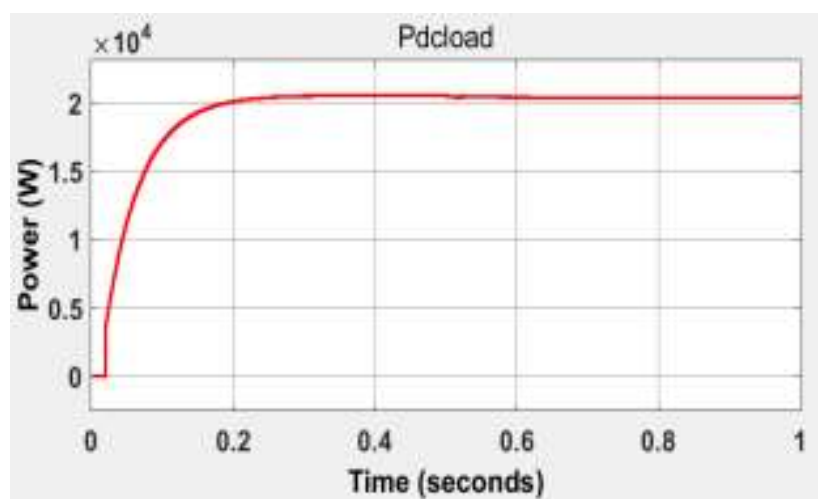

(b)

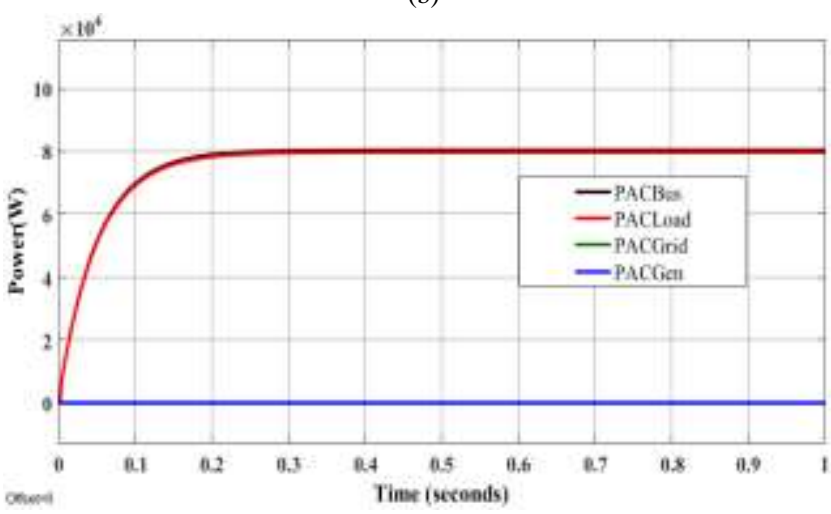

(c)

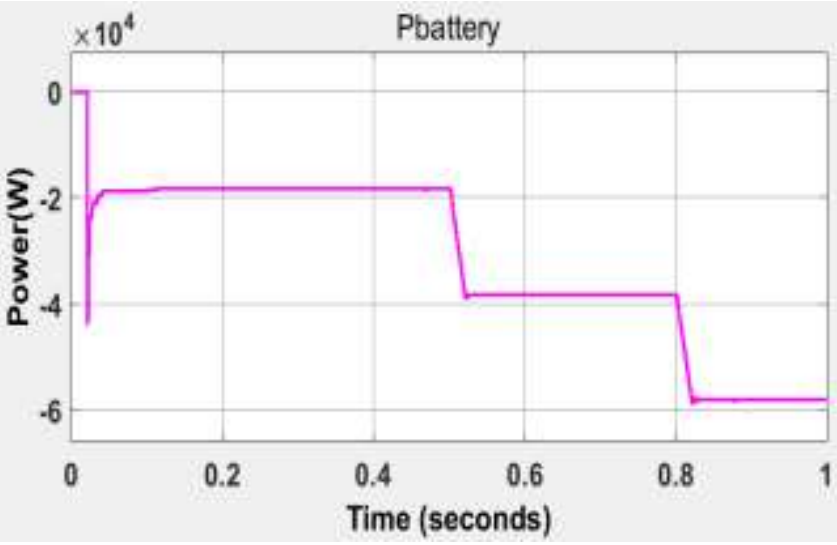

(d)

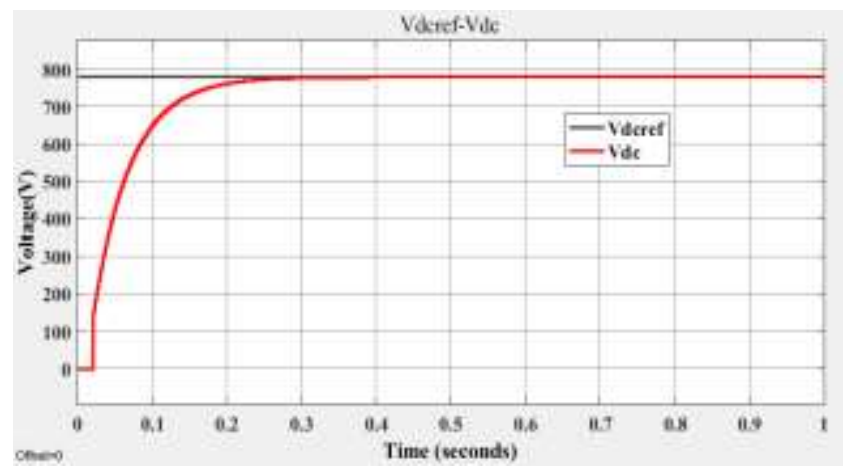

(e)

Fig 4. Irradiation changes condition; (a) PV capacity, (b) DC load (c) AC bus power, (d) Battery power and (e) DC bus voltage 
JAREE-Journal on Advance Research in Electrical Engineering

Volume3, Number 2, October 2019

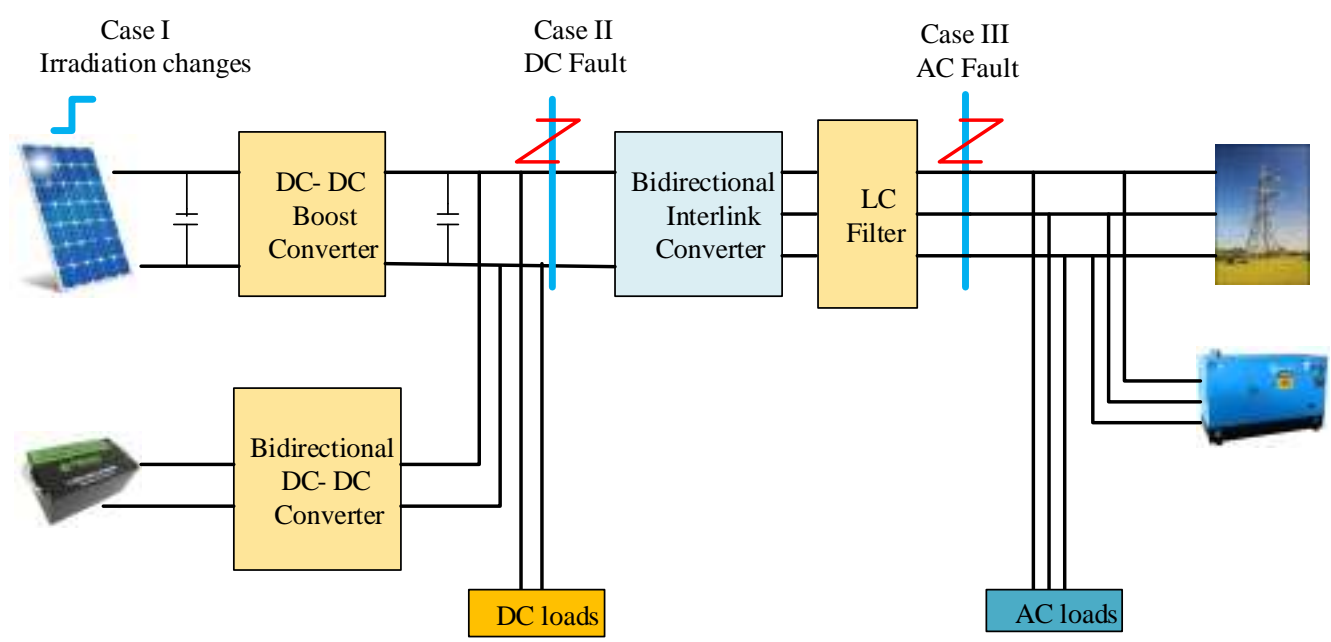

Fig 5. AC/DC hybrid microgrid mode

TABLE I. SYSTEM PARAMETERS

\begin{tabular}{|c|c|c|}
\hline Sr. No & Type & Value \\
\hline 1 & $\begin{array}{l}\text { PV } \\
\text { Rated Capacity } \\
\text { String Voltage }\end{array}$ & $\begin{array}{l}100 \mathrm{~kW} \\
380 \mathrm{~V}\end{array}$ \\
\hline 2 & $\begin{array}{l}\text { Battery } \\
\text { Capacity of Battery } \\
\text { Maximum depth of charge }\end{array}$ & $\begin{array}{l}200 \mathrm{Ah}, 780 \mathrm{~V} \\
80 \%\end{array}$ \\
\hline 3 & $\begin{array}{l}\text { Synchronous Generator } \\
\text { Output Capacity } \\
\text { Output Voltage } \\
\text { Internal Resistance }\end{array}$ & $\begin{array}{l}150 \mathrm{kVA} \\
400 \mathrm{~V} \\
0.029876 \mathrm{pu}\end{array}$ \\
\hline 4 & $\begin{array}{l}\text { AC Grid } \\
\text { Rated Capacity } \\
\text { Phase to Phase Voltage }\end{array}$ & $\begin{array}{l}1 \mathrm{MVA} \\
11 \mathrm{kV}\end{array}$ \\
\hline 5 & $\begin{array}{l}\text { Loads } \\
\text { AC load } \\
\text { DC load }\end{array}$ & $\begin{array}{l}100 \mathrm{~kW} \\
20 \mathrm{~kW}\end{array}$ \\
\hline
\end{tabular}

b) Case (II) : DC fault

In grid-connected condition, power flow is from $\mathrm{AC}$ bus to DC bus and battery is charged from 0-0.5s. When fault occur at DC bus, AC grid power was interrupted as shown in Fig 6(a). Fig 6 (b) and (c) show that DC load drops nearly to zero and battery produced high power due to DC fault at $0.5 \mathrm{~s}$. After isolation the DC fault bus by using DC breaker, the AC bus is maintained at $100 \mathrm{~kW}$ of AC load which is shown in Fig $6(d)$.

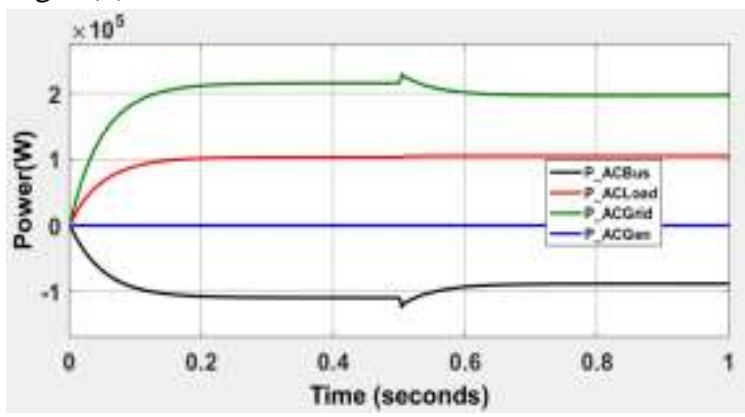

(a)

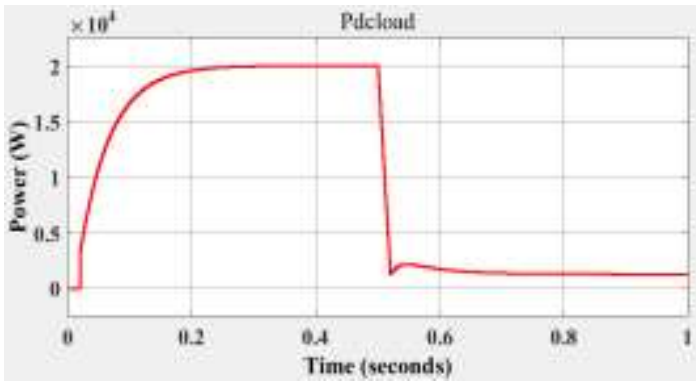

(b)

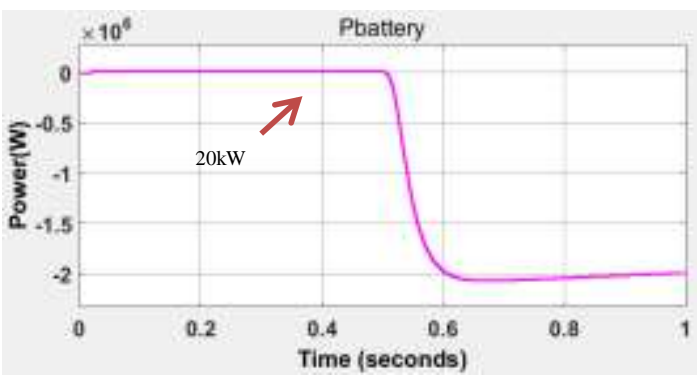

(c)

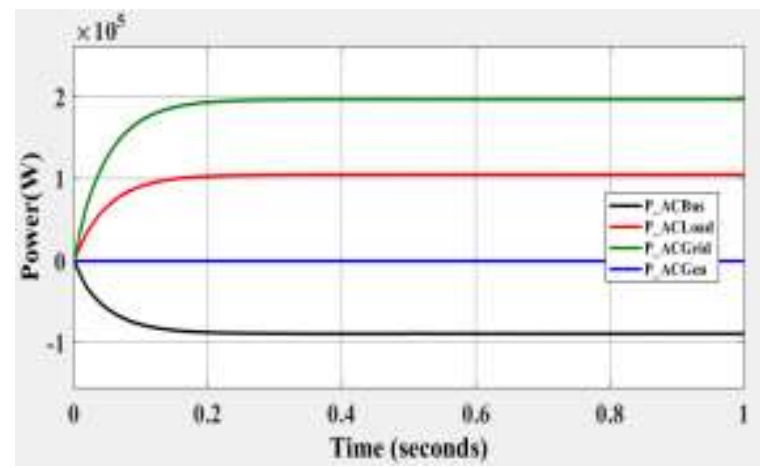

(d)

Fig 6. Fault at DC bus (a) AC bus power before isolation, (b) DC load, (c) Battery power and (d) AC bus power after isolation 


\section{c) Case (III) : AC fault}

When three phase fault occur in $\mathrm{AC}$ bus at $0.5 \mathrm{~s}, \mathrm{AC}$ grid off condition and the power flows from DC bus to AC bus although AC load have no power as shown in Fig 7 (a). Thus, DC load power is reduced to $18 \mathrm{~kW}$ as shown in Fig 7 (b).In this condition, the battery power discharge to DC bus as shown in Fig 7 (c). When AC breaker is used to isolate the faulty bus, AC grid is also off condition. In this condition, there is no power flow from DC bus to AC bus and AC load as shown in Fig 8 (a). Thus, the battery can discharge $20 \mathrm{~kW}$ to DC bus as shown in Fig 8(b). So, the DC load power is maintained $20 \mathrm{~kW}$ after isolation to the $\mathrm{AC}$ fault bus. This condition is shown in Fig 8 (c).

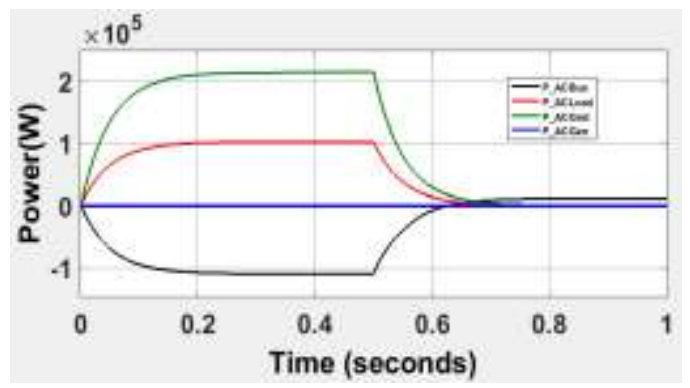

(a)

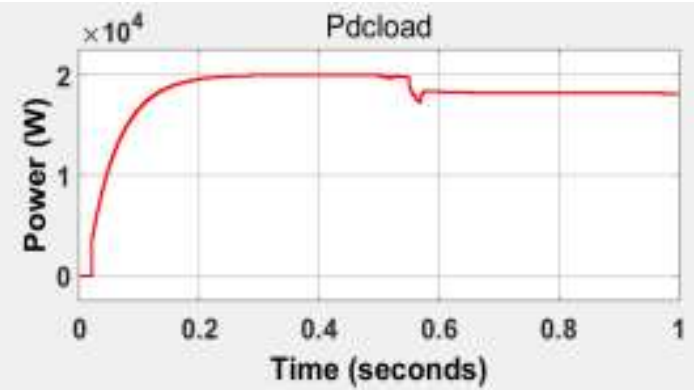

(b)

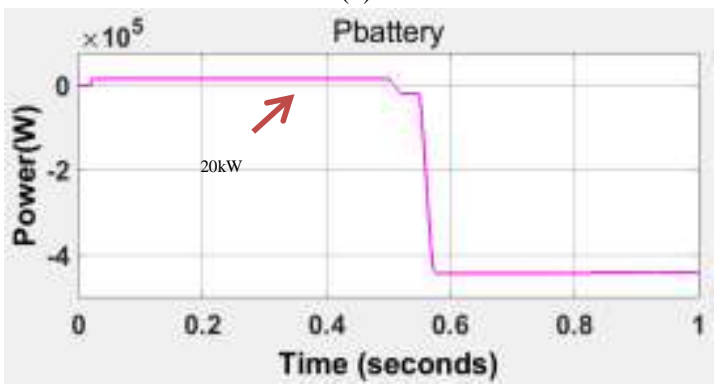

(c)

Fig 7. AC three phase fault, without isolation (a) AC bus power, (b) DC load and (c) battery power

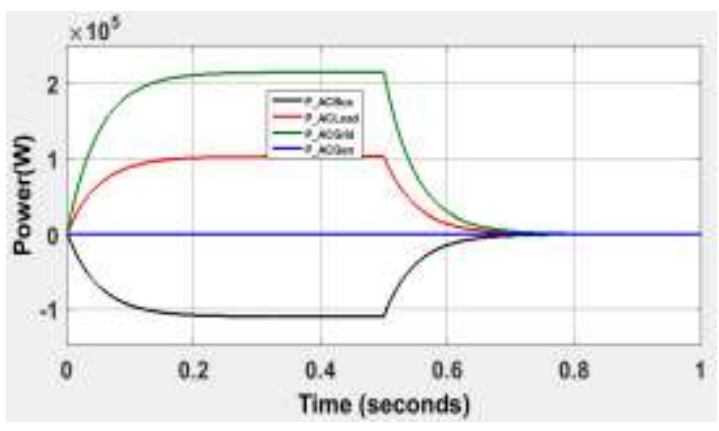

(a)

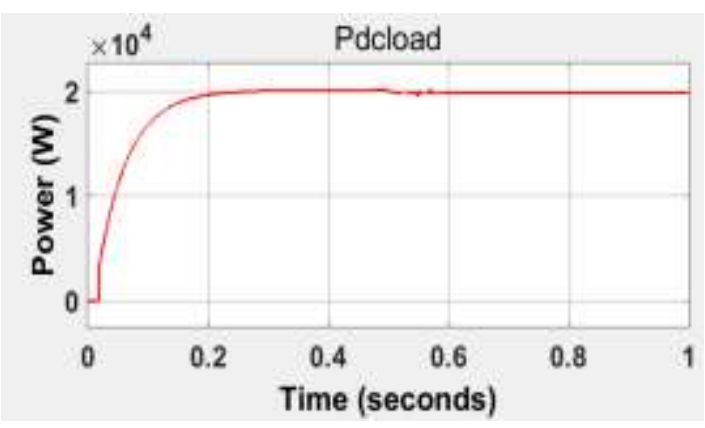

(b)

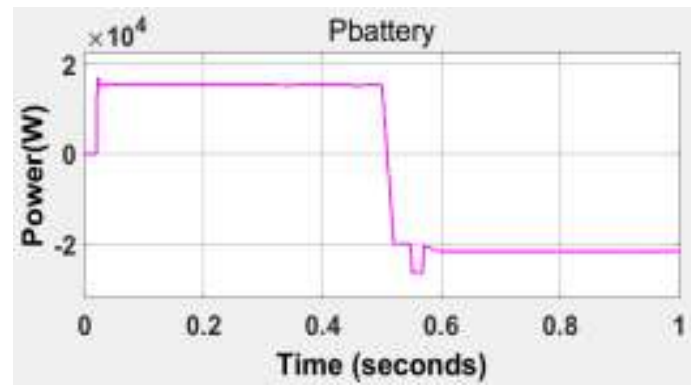

(c)

Fig 8. AC three phase fault, with isolation (a) AC bus power, (b) DC load and (c) battery power

\section{V.CONCLUSION}

In this paper, the bidirectional power flow of AC/DC hybrid microgrid under fault conditions is presented. The system consists of AC and DC subgrids connected by bidirectional interlink converter. In the system, droop control concept is applied for power sharing. AC circuit breaker and DC circuit breaker are used to isolate the system when AC fault and DC fault occur. To evaluate the performance of isolation circuit, AC fault and DC fault are applied at the simulation system. According to the simulation results, the system is isolated from the interrupted bus under both AC fault and DC fault conditions. Therefore, the protection scheme presented in this paper is reliable and protects for bidirectional interlink converter under fault conditions.

\section{REFERENCES}

[1] Li, Chendan; Chaudhary, Sanjay K.; Quintero, Juan Carlos Vasquez; Guerrero, Josep M. "Power flow analysis for droop controlled LV hybrid AC-DC microgrids with virtual impedane" Proceedings of the IEEE Power \&amp; Energy Society General Meeting, PES 2014

[2] Octavian Cornea, Gheorghe-Daniel Andreescu, Nicolae Muntean, and Dan Hulea, "Bidirectional Power Flow Control in a DC Microgrid Through a Switched-Capacitor Cell Hybrid DC-DC Converter" IEEE Transactions on Industrial Electronics, Vol.64, No 4, April 2017.

[3] Girija .R, Dr.Arivalahan .R, "Power Management and Decentralized Control of Interlinking Converter by Interfacing AC and DC Micro grids", IJESIT, Volume 3, Issue 6, November 2014

[4] Hema V K and R Dhanalakshmi "Analysis of Power Sharing On Hybrid AC-DC Microgrid”, IEEE 2014

[5] Akbar Dadkhah, Navid Bayati, Behrooz Vahidi and Seyed Hossein Hesamedin Sadeghi, "On the Stability of Hybrid AC-DC Microgrids in Various Loads and Short Circuit Faultas Conditions" Sci.Int.(Lahore),27(4),3099-3104,2015 
JAREE-Journal on Advance Research in Electrical Engineering Volume3, Number 2, October 2019

[6] M.Shamily and M.Saravanan, "Autonomous control of interlinking converter in hybrid PV-wind microgrid”, (IOSR-JEEE) e- Volume 10, Issue 1 Ver. III (Jan - Feb. 2015)

[7] Hyeon-Kyun Ji, Hyeong-Jun Yoo, Thai-Thanh Nguyen, and Hak-Man Kim , "Applying Improved Droop Control to Hybrid Microgrid Control", International Journal of Control and Automation Vol. 8, No. 7 (2015), pp. 395-404

[8] Xialin Li, Member, Li Guo, Yunwei Li, Zhen Guo, Chao Hong, Ye Zhang and Chengshan Wang, "A Unified Control for the DC-AC Interlinking Converters in Hybrid AC/DC Microgrids", IEEE 2016

[9] Dwi Riana Aryani, Jung-Su Kim ID and Hwachang Song, "Interlink Converter with Linear Quadratic Regulator Based Current Control for Hybrid AC/DC Microgrid”, Energies 2017.

[10] Saeed Peyghami, Hossein Mokhtari and Frede Blaabjerg, "Autonomous Operation of a Hybrid AC/DC Microgrid with Multiple Interlinking Converters"2018
[11] A. Shabani, K. Mazlumi "DC Microgrid Protection in the Presence of the Photovoltaic and Energy Storage Systems" JOAPE Vol. 6, No. 2, Dec. 2018

[12] Muhammad H. Rashid, "Power Electronics Handbook", 2011

[13] Dwi Riana Aryani and Hwachang Song "Coordination Control Strategy for AC/DC Hybrid Microgrids in Stand-Alone Mode" energies 2016,9,469, V

[14] Chitra Natesan1, Senthilkumar Ajithan, Shobana Mani, and Prabaakaran Kandhasamy, "Applicability of Droop Regulation Technique in Microgrid - A Survey”, Volume 18 Issue 3, 10 July 2014

[15] Megha Goyal and Arindam Ghosh, "A Phase-Locked-Loop Desigh for the Smooth Operation of a Hybris Microgrid”, AUPEC 2013

[16] Mustafa Farhadi "Hybrid Energy Storage Implementation in DC and AC Power System for Efficiency, Power Quality and Reliability Improvements" 2016 